\title{
Histopathology of Klebsiella pneumoniae strain Borkar inciting root bark necrosis and wilt in pomegranate
}

\begin{abstract}
Histopathology of root bark necrosis and wilt in pomegranate incited by Klebsiella pneumoniae strain Borkar revealed that the bacterial infection was non- vascular in nature. The bacteria infect the epidermal layer and cortex of the bark tissues which are easily peeled off. Due to absence of root bark, the absorption of water and food material is hindered which results in wilting of the pomegranate plant.

All other plant pathogenic bacteria inducing wilting in other plants infect the vascular system of the plant which finally leads to plant death, however the Klebsiella pneumoniae strain Borkar inciting root bark necrosis and wilt in pomegranate differed from other plant pathogenic bacteria by infecting only the cortex and epidermal cells of root bark to induce wilting in infected pomegranate plants.
\end{abstract}

Volume 5 Issue 5 - 2018

\author{
Borkar SG, Ajayasree TS \\ Department of plant pathology and agricultural microbiology, \\ Mahatma Phule Agricultural University, India
}

\begin{abstract}
Correspondence: Ajayasree TS, Department of plant pathology and agricultural microbiology, Mahatma Phule Agricultural University, Rahuri-4I3722, Dist- Ahmednagar (MS), India, Fax 09I 02446-245I4I, Email ajayasreel28@gmail.com
\end{abstract}

Received: June 08, 2018 | Published: September 07, 2018

Keywords: histopathology; Klebsiella pneumoniae, root bark necrosis

\section{Introduction}

Soil borne plant pathogenic bacteria generally causes wilting symptoms by infecting the vascular tissues of plant root. During April 2015, the pomegranate plants in the Arid Zone Fruit Research Project, Mahatma Phule Agricultural University, Rahuri, India exhibited some unusually wilted plants. The symptoms included yellowing of leaves of one or two twigs, followed by their drooping and subsequent death of infected twigs. Subsequently other twigs also showed infection and the entire plant die within 2-3 months. The root system of infected plant shows root bark necrosis lesions spread on the root bark (Figure 1). There was no vascular infection present in the root. The wilting without vascular infection was unusual and therefore the histopathology of root infection was undertaken to assess the infection site and nature of infection in the pomegranate root.

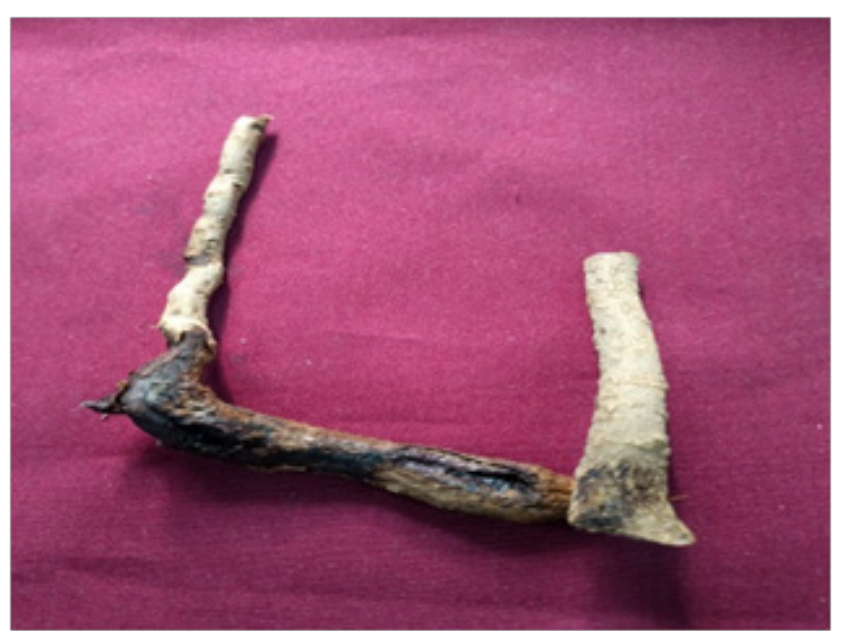

Figure I Symptoms of root bark necrosis on roots of wilted plant.

\section{Materials and methods}

\section{Performing of the string test}

The root bark necrosis infected roots of pomegranate plant were collected from the pomegranate orchard of MPKV, Rahuri. The infected root samples were washed thoroughly under tap water to remove dirt particles and air dried. These root portions were given a cut by using a sterilized scalpel and immersed it in sterilized distilled water to observe the bacterial string coming out from the vascular bundles of the infected portion of the root.

\section{Preparation of root sections for histopathology}

The root bark necrosis infected root sample was washed thoroughly under tap water and air dried. By using a microtome ultrathin transverse section of the infected root sample was taken. These transverse sections were taken on a sterilized clean glass slide in a drop of distilled sterile water. A drop of methylene blue strain was added on these sections. Excess stain was removed by using the tissue paper and root sections were cover with a clean cover slip and samples were observed under compound microscope.

\section{Results}

\section{String test}

The root bark necrosis infected samples did not produce the bacterial string from vascular bundles of root, indicating that the root bark necrosis bacterium Klebsiella pneumoniae did not infect the vascular bundles; however the formation of string was observed from the individual necrosis lesions on the root bark (Figure 2). In other bacterial wilt diseases, the pathogen infects the vascular bundles and the infected root shows the string formation from the vascular bundles. ${ }^{1}$ 


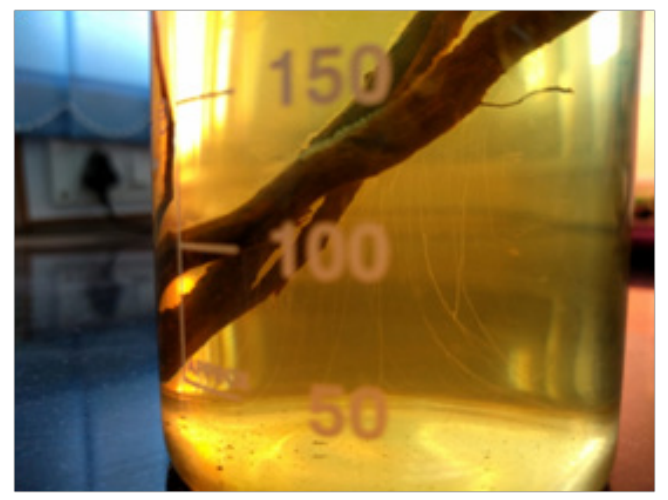

Figure 2 Formation of string from the root bark necrosis lesions.

\section{Infection site of Klebsiella pneumoniae in root system}

The microscopic observations of the transverse sections revealed that the bacteria infect the root bark comprising epidermis and cortex tissues and the bacteria were present in these tissues (Table 1). Such tissues were easily peeled off or were absent in the necrosis infected sections (Figure 3) whereas in healthy root sections the root bark comprising epidermis and cortex layer were intact. The xylem and phloem tissues were not infected. Thus the infection of plant pathogenic Klebsiella pneumoniae strain Borkar inciting root bark necrosis and wilt in pomegranate was non-vascular in nature.

Table I Infection site of Klebsiella pneumoniae in pomegranate root

\begin{tabular}{lll}
\hline Sr. No. & Type of tissue & $\begin{array}{l}\text { Presence or absence of } \\
\text { bacterium }\end{array}$ \\
\hline 1 & Epidermis & + \\
2 & Cortex & + \\
3 & Endodermis & - \\
4 & Medullary ray & - \\
5 & Xylem & - \\
6 & Cambium & - \\
7 & Phloem & - \\
8 & Pith & - \\
\hline
\end{tabular}

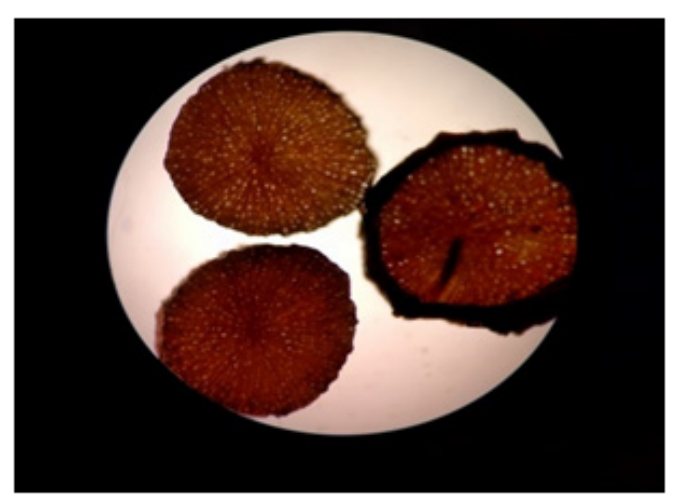

Figure 3 Removal of epidermal and cortex tissues by Klebsiella infection.

\section{Discussion}

The bacterial plant pathogens which infect the plant root to cause wilting are generally localized and infectious in vascular tissues. ${ }^{2}$ The presence of these bacteria in vascular tissues is shown by string test. ${ }^{1}$ However in pomegranate wilt the bacterial pathogen Klebsiella pneumoniae infect the root bark comprising of epidermal tissues and cortex and incite the root bark necrosis symptoms. Klebsiella pneumoniae does not infect the vascular tissues. The infection on root bark disintegrates the root bark and leaves the root without its bark.

In plants root bark help in water and nutrient absorption. The damage to root bark by Klebsiella pneumoniae and its removal from root system adversely affects the absorption of water and plant nutrition which gradually leads to wilting systems and complete death of the infected pomegranate plants. ${ }^{3}$

\section{Acknowledgements}

None.

\section{Conflict of interest}

The author declares that there is no conflict of interest.

\section{References}

1. Borkar SG. Laboratory techniques in plant bacteriology. USA: CRC Press; 2017. p. 256.

2. Borkar SG, Yumlembam RA. Bacterial diseases of crop plants. USA: CRC Press; 2016. p. 594.

3. Ajayasree TS, Borkar SG, Yumlembam RA. Root bark necrosis and wilt of pomegranate; A disease of new etiology. National symposium on diagnosis and management of plant diseases: Integrated approaches and recent trends. Indian phytopathological society held at ICAR Research complex for NEH region, Umium, India: Meghalaya; 2017. p. 98. 